\title{
El mestizaje contra el principio del tercero excluido*
}

Rodrigo Pérez Gil

Investigador independiente luzagosto2003@yahoo.com

\section{RESUIMEN}

El tercero incluido no solo rescata y valora lo desarreglado, lo descompuesto, el valora como hecho clínico la mezcla de desecho, el desperdicio, lo ruinoso, el cadárazas, sino también las anomalías de todo tipo, los freaks, los desviados, todo aquello ver mismo, en lucha contra el terrorismo de que se aparta del patrón hombre (especie las apariencias.

Palabras clave: mestizaje; tercerohumana)-varón-blanco-adulto-cristianoheterosexual-habitante-de-las-ciudadesexcluido; tercero-incluido; paradojas; puritanismo; ser; devenir; participación. 


\section{Inter-Ethnicity Against the Principle of the Excluded Third}

\section{ABSTRACT}

The included third not only rescues but also values as a clinical fact the mix between races, but also the anomalies of al type, the freaks, the deviated, everything and everyone who gets apart from the men pattern (human specie)-male-white-adultchristian-heterosexual-inhabitant-of-thenorth-cities. The included third rescues and values the broken, the unkempt, the waste, the refuse, the ruined the corpse itself, in a struggle against the terrorism of appearances.

Keywords: inter-ethnicity; excludedthird; included-third; paradoxes; puritanism; being; becoming; participation.

\section{A mestiçagem contra o princípio do terceiro excluído}

\section{RESUMO}

O terceiro incluído não só resgata e valoriza a mistura de raças como um fato clínico, mas também anomalias de todos os tipos, os freaks, os desviados, tudo que se distancia do padrão homem(espécie humana)-varão-branco-adulto-cristãoheterossexual-habitante-das-cidades-do- norte. O terceiro incluído resgata e valoriza o desarrumado, o decomposto, o lixo, o desperdício, o prejudicial, o próprio cadáver, na luta contra o terrorismo das aparências.

Palavras-chave: devir; miscigenação; paradoxos; participação; puritanismo; ser; terceiro excluído; terceiro incluído. 


\section{Introducción}

El presente ensayo es un manifiesto por el mestizaje y contra el principio del tercero excluido, cuya nefasta influencia en el pensamiento y en la vida social, humana, animal se intenta poner de presente. Para ello, se presentan casos que ponen en cuestión tal principio, tanto desde el punto de vista del pensamiento - las paradojas - como de la vida, e indaga acerca de los orígenes de dicho principio y su aplicación en la filosofía, las matemáticas y la moral corriente. Los puntales en que se apoya el principio de no contradicción o del tercero excluido son: el principio de identidad, el verbo ser, la relación sujeto-objeto y la partición en parejas cielo-infierno, humano y no-humano, hombre-mujer, blanco-negro, niño-adulto, heterosexual-homosexual, ángel-bestia, luz-oscuridad. O eres una bestia o eres un ángel, no los dos; o eres un hombre o eres un animal, no los dos; o eres hombre o eres mujer, no ambos; o eres blanco o eres negro, no los dos. De esta manera, tal principio tiende a negar la participación del hombre con el animal, del hombre con la mujer, del niño con el adulto, de la luz con la oscuridad, etc. La guerra que el hombre ha hecho contra el mundo y las guerras entre los hombres han bebido de estas fuentes de la exclusión y de las pertenencias.

En la Escuela de Minas, no más llegando a estudiar ingeniería, aprendimos la prueba por reducción al absurdo que se aplica para encontrar el número que mide la diagonal de un cuadrado de lado uno. Mucho antes, yo había conocido en el curso de Historia Sagrada del colegio la prueba de Abraham, a quien Yahveh, desde lo alto, conmina a hacer la cosa más baja: sacrificar a su propio hijo, Isaac. Abraham se turbó profundamente, Abraham dudó. Pero más grande que la turbación y la duda, era su fe que, a la postre, por el absurdo, salvó a su hijo y salvó su alianza con Yahveh. En la prueba por reducción al absurdo aplicada a la búsqueda de un número que mide la diagonal de un cuadrado de lado uno, se supone que un número racional (fraccionario) mide dicha diagonal y, por medio de razonamientos lógicos se llega, bajo esa hipótesis, a una contradicción, es decir, a una proposición que niega un principio de aritmética o de geometría. Por lo tanto, existe un número que no es racional. Esta prueba se atribuye a Hipaso de Metaponto. Pero tuvo que pasar mucho tiempo para encontrar o crear propiamente un número como raíz cuadrada de dos — número irracional que mide la diagonal del cuadrado de lado uno- usando el teorema de Pitágoras.

Consideremos ahora al mentiroso que dice "yo miento" ¿ Dice verdad o dice falsedad? Una de dos. Pues resulta que dice verdad y dice falsedad al mismo tiempo. Esta es una paradoja. Las paradojas contrarían el principio de no contradicción o principio del tercero excluido, y son la pasión del pensamiento. Así sucede en el caso de Alicia de Lewis Carroll (2010) y en el caso de la Lógica del sentido en Gilles Deleuze (2005). También sucede en el modesto caso de este 
ensayo, donde resaltamos el espectro político de este principio minado por una simple y desafiante declaración: "yo miento".

El principio de no contradicción se apoya en el principio de identidad, y la relación sujeto-objeto refuerza dicho principio: el animal está allá, objeto; el hombre está aquí, sujeto. Así, este principio tiende a negar la participación del hombre con el animal, del hombre con la mujer, del niño con el adulto, de la bestia con el ángel, de la luz con la oscuridad, etc.

Sin exagerar, se puede decir que este mero principio del tercero excluido, inscrito y encarnado en las conductas humanas, ha servido de alimento para buena parte del horror sombrío y el terror inicuo de la civilización moderna, llámese colonialismo, racismo, xenofobia, homofobia, gitanofobia, nazismo, estalinismo, patriotismo, nacionalismo, intolerancia de las pertenencias, exacerbado horror a los pobres, tan común a los puritanos y, sobre todo en América Latina, una misoginia y una homofobia acendradas e insólitas.

Se trata de aglutinar alrededor del principio, como en un mosaico, fragmentos o cuerpos heterogéneos que vienen a componerlo en su dimensión social, ética, estética, política, antropológica. Es como una manera de (des)investir o desnudar una entidad marciana e incitar a la creación de un paradigma inclusivo en el pensamiento y en la vida — una entidad venusina-, teniendo en cuenta que, tanto en un ámbito como en el otro, somos todos mestizos...

Los primeros españoles llegados a América, durante un tiempo considerable, vinieron de España sin mujeres blancas a las costas del Caribe. Con muy pocos buenos modales en la mayor parte de los casos — siendo ellos unos hombres buenos para imponer y apropiarse y malos para seducir-, se juntaron con mujeres indias y más tarde con mujeres negras siempre en la posición del misionero; el blanco barbudo encima y la india o negra quieta debajo. Estas fueron nuestras queridas primeras madres, de las que nos avergonzamos demasiado tiempo hasta recuperar la dignidad que los vencedores borraron en los vencidos al imponerles sus propios valores, lo cuales se fundan en la discriminación y en la segregación de los que "no son como nosotros" y han de ser como nosotros mediante un adoctrinamiento.

Lo que sigue va en nombre de todas las mezclas habidas y por haber entre las cuatro razas, blanca, mora o gitana, india y negra: mestizos, mulatos, zambos, cuarterones, octavones, chinos, saltapatrás, lobos, jíbaros, cambujos, zambiagas, calpamulatos, tente en el aire, etc. Va también en memoria de Fernando González, Gilles Deleuze y de Michel Serres, cuyas obras clarividen- 
tes y joviales, incluso en medio del desastre, inspiran este texto y alientan la vida. Y va en nombre de la fecundación cruzada entre el abejorro y la orquídea Ophrys bombyliflora.

En 1915, Fernando González cursaba quinto de bachillerato en el colegio de San Ignacio, y un día un cura lo conminó: o acepta "el primer principio de los jesuitas", el principio de no contradicción, que "una cosa no puede ser y no ser al mismo tiempo", o lo echamos del colegio (González, 1936). Pues lo echaron. Terminó en el Liceo y se graduó como abogado en la Universidad de Antioquia con el texto Una tesis. El derecho a no obedecer (González, 1919). Él creía que una cosa puede ser y no ser al mismo tiempo.

La historia de la Agencia Federal Antinarcóticos en Estados Unidos sirve como botón de muestra de algo que puede ser y no ser al mismo tiempo. Harry Anslinger, primer zar antidrogas, piedra fundadora de la guerra contra las drogas entre los años 1914 y 1960 en Estados Unidos, echaba pestes y lanzaba rayos y centellas contra las drogas, heroína, opio, morfina, cocaína, marihuana, y contra la población negra, hispana o china que las consumía. Pero, al mismo tiempo, como director de la agencia, daba una licencia a Coca-Cola para destilar hojas de coca traídas expreso desde Bolivia, y así fabricar la "chispa de la vida", bebida que contenía diez gramos del alcaloide por un litro de la bebida azucarada. La misma agencia de control de drogas se convertiría en el mayor proveedor de heroína en los Estados Unidos, y muchos de sus agentes, blancos puritanos, no tenían reparos en violar a una mujer negra adicta por el solo hecho de ser adicta y de ser negra, o sea, por estar, según ellos, en lo más bajo de la escala social. Si además de negra y adicta, era artista del jazz, como Billie Holiday, inspirada compositora y cantora, entonces se podía arremeter contra ella sin misericordia, como lo hizo Harry Anslinger, que confiscó los objetos personales de Billie al final de su vida - un radio, un tocadiscos, libros, flores-, mientras ella permanecía esposada a una cama de hospital, adicta a la heroína, con una cirrosis hepática severa por el alcohol y problemas cardio-respiratorios por el tabaco, poco antes de morir. Billie Holiday, o Lady Day (señora día), compuso y cantó una canción prohibida en los años treinta y cuarenta en los Estados Unidos, una canción que Anslinger no soportaba oír: "Los árboles del Sur cargan un extraño fruto / Sangre en las hojas y sangre en la raíz"1 (Holiday, 2011).

Una cosa puede ser y no ser al mismo tiempo. El puritano Harry Anslinger, al servir de vehículo para imponer la prohibición de las drogas cuya demanda estaba asegurada - pues resulta imposible erradicar del todo el consumo de drogas - creaba, de esta manera, el negocio del mercado negro de esta, puesto que la prohibición encarecía sobremanera el precio de la mercancía, lo que hacía

"Southern trees bear a strange fruit / Blood on the leaves and blood at the root". 
sumamente rentable comerciar con ella. Aparecen, entonces, los carteles de la droga y de alcohol en los Estados Unidos — con Al Capone a la cabeza-, gracias a la prohibición de estos entre 1918 y 1931. Así pues, el prohibicio-purita-nismo, que pretendía erradicar de la faz de la tierra el consumo de drogas ilícitas, le estaba entregando en bandeja de plata el narcotráfico a los Carteles de la droga. En sus últimos días, aquejado por una angina de pecho, ironía de las cosas, Harry Anslinger se aplicaba inyecciones de morfina para apaciguar el dolor.

Apreciemos estos otros casos donde una cosa es y no es algo al mismo tiempo: un trompo, si alcanza suficiente velocidad, fija su punta al suelo, está quieto $y$ se mueve, es estable y a la vez gira en torbellinos; por ello, sirve de modelo del mundo en miniatura. Otro caso es una obra de Marcel Duchamp, en la que vemos una puerta que se abre y se cierra al mismo tiempo sobre espacios diferentes. Un ejemplo más: la flecha avanza en un sentido, hacia un blanco determinado $y$, a la vez, gira, cambia de sentido, rota mientras se desplaza.

Esto de dirigirse en un sentido, pero cambiarlo al mismo tiempo, parece contradictorio. Para la flecha hay un sentido, la traslación que tiene como destino el blanco de la flecha, pero ocurre que ese sentido engendra al otro sentido, la rotación. Los contrarios cohabitan en la caja negra de las cosas. (Pérez, 2015, p. 153)

La orquídea Ophrys bombyliflora tiene modelado un abejorro pintiparado en su corola. Incluso, este segrega la fragancia de la hembra del abejorro para atraer mejor al abejorro macho que ha de llegar y copular con ella, impregnarse de polen y llegar a fecundar otra orquídea lejos de la primera para enriquecer, con esta fecundación cruzada, los cromosomas de la planta que se empobrecería con la endogamia. Este es un privilegiado ejemplo de mestizaje: este encuentro entre seres de reinos distintos, una planta y un animal, la orquídea y el abejorro. La orquídea, de cierta manera, es abejorro al haber captado parte de su código y modelar, en su corola, una especie de abejorro bien real para el abejorro macho que llega a copular con ella. Y el abejorro, de cierta forma, es orquídea por ser una pieza del aparato de reproducción de esta.

Aquella racionalidad aristotélica y jesuítica, la cual asevera que una cosa no puede ser y no ser al mismo tiempo, misma del Hamlet melancólico que cavila en la disyunción exclusiva ser o no ser, se basa en el principio de identidad y en la categoría misma de ser. "Acuérdate bien de andar con las puntas de los pies hacia afuera. Y ino te olvides nunca de quién eres!", le dice la Reina Roja a Alicia en la novela de Lewis Carroll (2010). Esta racionalidad del "identifíquese" o del "iusted no sabe quién soy yo?", combate por la permanencia o estabilidad de un yo contra la intrusión o intromisión de un doble o de un tercero: o uno es blanco o es negro, no los dos, no puede ser blanco y negro; es hombre o es mujer, no los dos, no puede ser hombre y mujer; o es heterosexual o es homosexual, 
no los dos; o es una bestia o es un ángel, no ambos; o es de día o es de noche, pero no ambos. Y, sin embargo, el crepúsculo, dicho en inglés twilight, nombra unos momentos como a dos luces entre el día y la noche, unos momentos en que todavía es de día y ya es de noche. Cuántas veces uno muere y está vivo, vive y está muerto. El mal es la sombra del bien. Las líneas rectas no existen en la naturaleza ni en la vida; ni en las cosas existen las líneas curvas, las elipses, las espirales y los remolinos.

Paradojas: "Así pues quien desea la paz, que prepare la guerra (Vegecio, 2006, p. 241), "[s]olo sé que nada sé" (Platón, 1871), "[s]eamos realistas, pidamos lo imposible"2. Objetos paradójicos: la cinta de Moebius, en la que se pasa de un lado al otro de la cinta sin cambiar de lado, tiene una sola cara; el uróboro, serpiente que se muerde y se traga por la cola, símbolo del capitalismo autófago. Al final, ¿dónde está la serpiente? La serpiente entera se hallaría dentro de su propio estómago. Una paradoja lógica elemental es la del mentiroso, uno que dice simplemente "miento". Supongamos que dice verdad, entonces es verdad que miente: contradicción. Supongamos que miente, entonces está diciendo la verdad dado que dice que miente: contradicción. O sea, este hombre, a la vez, miente y dice la verdad. De la paradoja aflora la contradicción; "el cortocircuito sirve para ilustrar las paradojas y también los devenires que conjugan pasado y futuro: el negativo invita al positivo, el positivo invita al negativo, y el círculo se completa. La paradoja afirma los dos sentidos a la vez" (Pérez, 2015, p. 161), como el devenir de Alicia: devenir más grande de lo que era y más pequeña de lo que será, y las dos direcciones del tiempo, pasado y futuro, a la vez.

Las paradojas contrarían el principio del tercero excluido. Este declara que algo es esto o es lo contrario, de manera excluyente, no ambas cosas a la vez. O te vas pa'l cielo o te vas pa'l infierno, una de dos, el paso por el purgatorio es pasajero. Las paradojas afirman una cosa y también la contraria, así como la vida, donde se encuentran pasajes celestes o solares y pasajes lunares o infernales. Las paradojas se abren, de esta manera, al principio del tercero incluido y son el corazón del devenir. Ellas, que pertenecen al pensamiento tanto como a la vida, afirman dos sentidos a la vez.

Mientras que la ciencia y el pensamiento habrían asimilado el sentido de las paradojas y el principio del tercero incluido luego de que se descubrieran las geometrías no-euclidianas, por ejemplo, resulta que en las instituciones, en la política y en la moral corriente sigue prevaleciendo una cultura heredada del antiguo Occidente (Pérez, 2015). Esta cultura occidental sigue muy interesada en el control que da preponderancia al ser, al sujeto, a la identidad, al principio

Esta frase se expresó con frecuencia durante la Revolución de mayo de 1968 en Francia. No tiene autoría clara, se le atribuye en algunos casos al filósofo Herbert Marcuse (no se publicó en alguna de sus obras como tal dicha frase), a Ernesto "el Che" Guevara, entre otros. 
del tercero excluido y al puritanismo a él asociado. Niega las mezclas y trabaja con la partición del cielo y el infierno, del inocente o culpable, del bien y el mal, de la bestia o el ángel, etc.

En la vida y en las cosas, los contrarios cohabitan, conviven todo el tiempo. Vivimos en las mezclas, entre el orden y el caos, entre lo bueno y lo maluco, entre el saber y la ignorancia, "contiguos, entre la ternura y el espanto, entre el éxtasis por lo inefable y el sentido de lo irrisorio y lo abyecto, entre risas y lágrimas, entre lo más alto y lo más bajo" (Pérez, 2015, p. 161), entre lo sano y lo enfermo, entre el cielo, el purgatorio y el infierno...

La niña camina y camina durante un buen trecho y, sin embargo, cada vez que el camino se bifurca se encuentra con las mismas señales, unos índices de manos apuntando en la misma dirección. Uno decía: "A casa de Tararí" y el otro decía: "A casa de Tarará". Gemelos, salvo porque uno es la imagen en el espejo del otro. (Pérez, 2015, p. 175)

Así, Tararí tiene un lunar en la mejilla izquierda y Tarará lo tiene en la derecha.

Actúan distinto y hasta pelean. Sin embargo, cuanto más se diferencian más nos parecen iguales. La pelea entre Tararí y Tarará porque uno le quitó un sonajero al otro y lo echó a perder, evoca terribles guerras civiles de una época anterior a los Tudor en Inglaterra, en las que el pueblo llevó del bulto en manos de facciones que, en el fondo, eran muy parecidas o idénticas y al pueblo muy poco le importaban (Pérez, 2015, p. 175).

Esta situación se parece mucho al llamado "conflicto" en Colombia y las confrontaciones entre facciones, bien fueran liberales y conservadores, guerrillas, paramilitares y ejército, aunque el trofeo sea algo más que un sonajero como en el caso de Tararí y Tarará; "la cosa es que las minorías en Colombia han llevado parejo y siempre del bulto, han sido presa del afán de hacer Estado común al Estado establecido, a las guerrillas y a los paramilitares" (Pérez, 2015, p. 175); todos son pretendientes de Estado que, cuanto más se diferencian porque son distintos, más nos parecen iguales: monstruos gemelos. Todos quieren mandar, y todos cobran un tributo por mandar y por proteger a la población, dicen ellos, del miedo que ellos mismos esparcen.

En una de las guerras civiles en Inglaterra, en la alternativa siempre peligrosa de caer en manos de facciosos de uno u otro bando, Lewis Carroll, a la pregunta sobre qué lado está — si de Guillermo o de Ricardo—, habría respondido: "estoy del lado de Guillardo". Son las palabras-perchero que se inventó Carroll para salir del atolladero liberal o conservador: ilibervador! Y es la realización plena del principio del tercero incluido. Entre uno u otro, escojo los dos; entre la bestia 
y el ángel, escojo la bestia y el ángel. La obra paradójica de Lewis Carroll tiende entera a deshacer la fuerza y presencia del principio del tercero excluido tan en boga en toda la época victoriana. Esta época, puritana por antonomasia, o sea, amante de las dualidades y de las particiones,-rasgo común al racismo, la xenofobia, la homofobia, la misoginia, el fanatismo, la intolerancia y a las guerras-, no tiene otro fundamento que la propiedad y la pertenencia: "Yo soy de los blancos, los buenos somos más".

En el combate entre Tararí y Tarará, "la irrupción de un monstruoso cuervo más negro que todo un barril de alquitrán y tan grande que eclipsó el sol de la tarde, hizo que nuestros héroes se asustaran tanto que se olvidaron de todos sus duelos" (Pérez, 2015, p. 175) ¿Irrumpirá el cuervo en la actual y muy vieja guerra que el hombre ha hecho contra el mundo, desde la cuna, desde el origen?

Afectada por el calentamiento global que trae la crecida de los mares y trastornos en los ciclos del agua, la Tierra puede replicar en la forma de un colosal cuervo negro. Tal vez así hará que los hombres, como cuando se está hundiendo un barco sin chalupas de salvamento, dejen de combatir entre sí y dejen de combatir contra el mundo para unirse y aunar esfuerzos tendientes a la recuperación del barco en peligro de zozobrar. Esta es la "utopía activa" de Michel Serres. La pintura de Goya que muestra dos colosos en un Combate a garrotazos, sumergidos hasta los tobillos en unas arenas movedizas, suscita la idea del espectador que apuesta por uno u otro de los colosos: ¿Quién ganará? ¿Tararí o Tarará? Mientras mayor es el furor en el combate, más se hunden los dos contrincantes en el cieno. ¿Quién ganará? ¿La China o los Estados Unidos? ¿Estados Unidos o Irán? iPero hay un tercer contrincante, la Tierra! ¿Ganará la Tierra hundiendo a ambos colosos?

La categoría del ser, fundada por Aristóteles, trajo la categoría de la relación sujeto-objeto asentada en la Edad Media: el objeto gira alrededor del sujeto como la Tierra alrededor del Sol. Es el ego-narciso-parásito que ve plegarse los animales, las plantas, los minerales y todas las cosas a su voluntad de apropiación cumpliendo el mandado de Yahveh en el Génesis (2006): "Tengan muchos hijos, para que llenen toda la tierra, y la administren. Ustedes dominarán a los peces del mar, a las aves del cielo, y a todos los animales que hay en la tierra" (1:27-29). Se trata de la lucha del ser contra el devenir y contra el mundo, la lucha del yo contra la multiplicidad y la variabilidad.

Así construida, esta metafísica que refuerza el sujeto tiende a negar la participación del hombre con el animal, del hombre con la planta, del hombre con la materia. El primer "blanco aborigen" o el primer "aborigen blanco" en América según D. H. Lawrence, Walt Whitman (1997) descubre, en Canto a mí mismo, que ha asimilado granito, carbón, musgo, frutos, semillas, raíces..., y 
que todo su cuerpo está impregnado de cuadrúpedos y de pájaros. Declara que ha dejado atrás, por razones esenciales, las formas inferiores, pero que puede hacerlas volver a él cuando quiera.

En efecto, provenimos de estas formas inferiores y, en condiciones de extrema urgencia, mediante un trabajo o una mediación, se pueden recuperar el animal, la planta, la materia. Ocurre que la vida es un predicado, es una relación. No es algo que está en los sujetos, sino que es algo que pasa a través de los sujetos. La vida es lo que está entre: entre los seres humanos, las plantas y los animales. La lógica de la vida no es una lógica del ser, sino del devenir: devenir-planta, devenir-animal, devenir-mujer, etc.

A propósito del ser, en su obra Hominiscencia, Michel Serres (2003) nos dice que el verbo "ser" concierne a las bestias, a las plantas, a los hongos y bacterias, al fuego, al aire y a las nubes. Sin embargo, los hombres habitamos más bien en las modalidades de lo posible, lo imposible, lo necesario y lo contingente. El verbo existir, literalmente, sugiere ya la idea de lo que está por fuera del equilibrio. ¿Qué somos, pues, en últimas? Inesperados, aventureros, imprevisibles, buscadores, desobedientes... posibles y contingentes. Sí, el hombre tiene horror del ser...

Paul Cézanne logró invertir la relación sujeto-objeto al pintar las fuerzas de geminación de la manzana. Son fuerzas invisibles, pero bien reales, hechas visibles mediante la pintura y al final de la convicción lentamente lograda de que la manzana exista por su cuenta, como sujeto al margen del hombre. Había dicho que asombraría a París con una manzana, y logró su cometido. Hoy día y cada vez más, la Tierra, el objeto, se convierte en sujeto, y nosotros nos convertimos en objetos y renacemos en sujetos interpelados por ella.

\section{2}

En el texto "Anticristo: una química de las sensaciones y de las ideas" que aparece como introducción a su libro Hermes IV, Michel Serres (1977) produce una genuina inversión del platonismo. Fue un aduanero en Nueva York, a la llegada del barco que venía de Europa por los años 1960, quien le preguntó, al mirar su pasaporte y oler su equipaje, si traía queso francés dizque para prevenir un contagio. Esto fue, cuenta el autor, lo que lo motivó a escribir este ensayo. Se trata de una reflexión acerca del fenómeno de la fermentación, la dualidad y la partición, tan queridas por Platón y por el puritanismo. Pretenden vivir siempre y en todas partes en el cielo de las ideas, lejos del mundo material, lejos de la vida, lejos de la mugre bajo las uñas. Para Platón, la materia nunca será objeto de conocimiento, no quiso hacer migas con esta y la despreció. La materia está ligada al devenir, de ahí la inestabilidad, y a la mezcla, que es una forma de 
desorden para el filósofo. Platón valora la fijeza, la pureza, la verdad y la esencia sin mezcla, caracteres de aquellas cosas que están siempre en el mismo estado sin cambios ni aleaciones. En cambio, desprecia todo lo demás, que debe ser considerado como secundario e inferior. La reflexión de Serres (1977) tiene como soporte el queso francés.

De paso, nos da una lección de vida para vivir mejor en el tercer mundo y en cualquier parte, y para aprender a acoger las mezclas, el mestizaje, a convivir con el mal y a encontrar un sentido a la podredumbre, descomposición y cambio de sustancia. (Pérez, 2015, p. 161)

La descripción anterior es obra de la fermentación que ocurre por acción de una levadura. El queso aclimata la podredumbre, ni más ni menos. Es una leche expuesta a la mugre y transvaluada en un estado superior. La levadura, un "hongo pequeño y vil invade y mancha la blancura del lacticinio. Un cultivo, un caldo de cultivo, de allí el nacimiento de una cultura" (Pérez, 2015, p. 162). Separar, eliminar lo sucio, asegura Serres (1977), conduce a un vivir aséptico y cerrado en medio de un espacio de basuras. Es el resultado de la dicotomía. Lo mismo ocurre con el cuerpo: un organismo protegido del miasma es frágil y ya está enfermo. Aquí manda la parada, justamente, la ley del tercero excluido, la dicotomía de lo sucio y lo limpio, "en breve, la partición en general es la enfermedad. El infierno es la separación del paraíso y el infierno" (Pérez, 2015, p. 162). Lo que nos importa sobremanera es el hecho de que la sabiduría y la verdad científica aclimatan lo venenoso, lo blando, lo podrido, lo corrompido, el mal y la enfermedad misma. Importa saber lo sano más allá de lo aséptico y lo fuerte más allá de lo protegido...

La salud, la vida, tienen la forma del queso...

En esta misma vena de Serres, François Dagognet (2002) escribió un libro, Desechos, detritos, lo abyecto, donde quiere privilegiar el sustrato, en contravía de la metafísica tradicional e idealista que minimiza el soporte en beneficio de lo que él difunde. Es el mismo gusto del burgués a la hora de apreciar un libro: le importa más lo que se dice que la manera de decir las cosas. Nos proponemos, dice Dagognet (2002), impedir las particiones y los tabicados que desigualan demasiado la sociedad, pues no se deja de disminuir y desvalorizar a los hombres que manipulan lo que ha sido previamente reprobado, porque es vil y ensuciador. Así, los que limpian letrinas, los recicladores, basuriegos, picapedreros y traperos son comúnmente despreciados. El autor, alejándose de una filosofía idealista tradicional, quiere revalorizar lo sucio, lo descompuesto y lo pobre, en particular, un tejido deshilachado, el polvo, la arena o el guijarro, hacerlos 'sujetos'. Nuestras sociedades, afirma Dagognet (2002), predican y practican un puritanismo material que haría necesario por todas partes limpiar, eliminar 
e incluso quemar. ¿Qué decir acerca del fenómeno de la muerte? Con relación a ella, el filósofo nos ilumina con una idea que, aunque ya está presente en la filosofía taoísta, es poco común, pues declara que la corrupción o la muerte, en lugar de entregarnos un cadáver, solamente asegura el paso de una forma a otra. Si no lo pensamos así, dice Dagognet (2002), es porque la primera forma que desaparece nos lo impone y nos parece la única positiva. Cedemos al terrorismo de las apariencias. Lo descompuesto o lo arruinado no anuncia tanto lo negativo, sino el comienzo de un retomar ulterior o un cambio de escena, pues no nos situamos aquí, dice el autor, en un plano económico del reempleo, sino en una perspectiva que excluye la muerte de lo sustancial. Dagognet (2002), que hace crítica y clínica en este ensayo, nos invita a no alinearnos sobre los prejuicios, los ascos y las fobias. En este sentido, no solamente promueve una socio-educación orientada hacia la "recuperación" de los desperdicios (remendar, etc.), sino sobre todo una psicoterapia gracias a un contacto con lo simple y lo desvalorizado. El enfermo mental, que sufre de un exceso de complicaciones y rumias, bien podría apaciguarse acompañándose de lo que está deteriorado, descompuesto; siempre que acepte volverlo a sacar de su noche material: posible enganche entre dos tipos de desterrados y despreciados.

El puritanismo inglés, amigo de las dualidades y las particiones, fue la manera como se expresó la época victoriana en la moral. Este puritanismo fue incubado originalmente en un horror exacerbado a la sífilis y demás enfermedades venéreas que habían cobrado sus presas y hecho estragos entre los nobles de la corona británica. De Inglaterra, el puritanismo se trasladaría a los Estados Unidos y a América. En la política colonial, la forma como se expresó esta época victoriana fue el racismo bajo la ley del tercero excluido, un racismo disimulado y apuntalado con la idea darwiniana de la supervivencia del más fuerte, del Darwin de El origen de las especies (1859), definitivamente no del Darwin maduro de Origen del Hombre. La selección sexual animal, donde afirma que la inadaptación es fuente de cambios que, eventualmente, mejoran las condiciones de vida.

Por supuesto, bajo esta opresiva y sofocante atmósfera puritana, que pregona la partición (cielo-infierno, bestia o ángel, bien o mal, heterosexual u homosexual) y el principio del tercero excluido, la misoginia y la homofobia se volvieron trofeos de caza, y los ingleses se sentían orgullosos de practicar la una y la otra. Es así como las autoridades llevaron a la cárcel y a la muerte a Oscar Wilde, y empujaron al suicidio a Alan Turing en 1952, inventor de máquinas de cálculo y decodificador de mensajes nazis durante la guerra, quien prefirió comerse una manzana con cianuro ante la alternativa de chupar cárcel o tratarse con estrógenos - macabra recompensa de los ingleses por su colaboración con los 
aliados en la Segunda Guerra Mundial—, por el "delito" de ser homosexual y tener a la vez una chispa de genio.

El origen del principio del tercero excluido no está en las matemáticas, ni en las Ideas como creería Platón, sino a posteriori, su origen remite más bien a un asunto antropológico. En El contrato natural, Michel Serres (1991) cuenta que Leibniz estimaba la finitud como un bien inapreciable por cuanto proporciona los límites que definen los lugares de propiedad "mis animales", "mi casa", "mi patria", como si lo propio del hombre se redujera a lo que él se apropia; confusión común que hace de las pertenencias una identidad. Ahora bien, todo cuerpo extraño que se aproxima a la frontera, que la cruza, se vuelve un enemigo a combatir. Imposible que él y otro permanezcan al mismo tiempo y en las mismas circunstancias en el mismo lugar: aquí están los principios de contradicción y de tercero excluido brotando, completamente armados, de la pertenencia, de la finitud o de la limitación. El origen del mal, tal como se lo imaginó Leibniz, proviene seguramente de la violencia producida en la vecindad de los límites por la exclusión del tercero. No solo la metafísica del yo, sino también la lógica más pura, encuentra su fundamento o al menos su equivalente en la antropología. (Pérez, 2015, p. 153)

En El incandescente, Serres (2005) invita a que nos vacunemos. Es una lección inmejorable sobre todo para nosotros, habitantes del Tercer Mundo, que acojamos el mal en pequeñas dosis para que nazcan algunas defensas posibles. En el horizonte, Mitrídates realiza lo ideal, de él se dice que aguantaba todos los venenos. Si el mal, la violencia y las drogas son imposibles de erradicar del todo, toca aprender a convivir con ellos. ¿Qué será, pues, el bien, se pregunta Serres,

si no la llama misma, la que consume en mí el mal que nunca me falta? Contra él hay que comenzar por un ejercicio de simbiosis individual: vivir con. ¿Cómo negociar este fango? Hago de él mi mejor combustible. La tolerancia al mal es una lección difícil de aprender. (Pérez, 2015, p. 147)

Es un hecho que los grandes tiempos de terror son los tiempos del tercero excluido. Antigua marca del judaísmo, el islamismo y el cristianismo, el puritanismo ha pretendido erradicar el mal ciento por ciento entre los hombres, humanos, demasiado humanos, que cargan con el legado de Caín y llevan la señal en la frente. Así, por ejemplo, los gobiernos puritanos de los Estados Unidos emprenden la guerra contra las drogas como si a lo largo de los siglos, en todas partes, no hubiera drogas de todo tipo que consume la gente. Además, la farmacia provee hoy día innumerables drogar. También son drogas la tele y las noticias tanáticas en los medios de comunicación masiva, la política, hablar o trabajar o escribir como loco, la droga que es el dinero, el alcohol, el tabaco, la erotomanía, la ambición y la búsqueda de fama o de reconocimiento, la sangre vertida. Todos ellos y ellas son drogas más o menos imperiosas. La adicción es lo que nos distingue de los animales, que no tienen horas, conciencia de la muerte ni sufren, como bien dice el poeta Jaime Gil de Biedma (1959): 


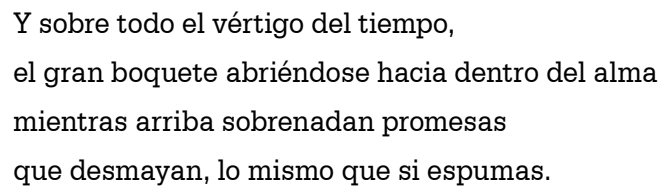

En un texto que escribió en 1989 para la revista Los niños primero, Serres declaraba que:

Las drogas funcionan como protecciones contra las angustias asociadas a la muerte y al tiempo. Es decir, todos los hombres, en todos los momentos y bajo todas las latitudes se entregan a la droga. Esta conducta, entre muchas otras, nos distingue de las otras criaturas del reino animal. Aquellos seres extraordinarios que saben o pueden vivir sin las drogas los denominamos, según nuestras culturas, sabios, justos o santos. (Serres, Pulido y Castrillón, 1995, pp. 68-69)

Todos somos mestizos, todos somos freaks, todos somos huérfanos y ha llegado la hora de la fraterna alianza por el cuidado de la Tierra a la par que por nuestro propio cuidado.

\section{Conclusiones}

El ensayo, en el mejor de los casos, logra sensibilizar al lector sobre el tema, no solo desde el punto de vista intelectual y del pensamiento, sino sobre todo, creemos, desde el punto de vista emocional, afectivo. De este modo, se realiza la idea del percepto en filosofía: una mezcla, precisamente, de percepción y afecto. Así como nunca más estarán separadas las ciencias de las artes, la literatura y la filosofía no estarán separadas de la vida y obra, pensamiento y afección, mente, alma y corazón.

La escritura de este ensayo funciona como revulsivo, como una purga estrictamente necesaria dado el estado de cosas reinante, y esperamos que tenga en el lector tan saludables resultados como para el autor del mismo.

\section{Agradecimientos}

El autor agradece a Luis Alfonso Paláu por darnos acceso, gracias a sus traducciones, a las obras de Michel Serres y de otros autores franceses contemporáneos.

\section{Referencias}

Carroll, L. (2010). Alicia en el país de las maravillas. Alianza.

Biblica. (2006). Nueva Biblia Viva. Biblica, Inc.

Dagognet, F. (2002). Detritus, desechos, lo abyecto: una filosofía ecológica (L. Paláu, trad.).

Deleuze, G. (2005). Lógica del sentido. Paidós. 
Gil de Biedma, J. (1959). Arte poética. Verseando. https://verseando.com/blog/jaime-gil-de-biedma-arte-poetica-de-\%C2\%B7companeros-de-viaje\%C2\%B7/

González, F. (1919). Una tesis. El derecho a no obedecer. Imprenta Editorial Medellín. https://www. otraparte.org/fernando-gonzalez/ideas/1919-tesis/

González, F. (1936). Los negroides. Editorial Atlántida. https://www.otraparte.org/fernando-gonzalez/ ideas/1936-negroides/

Holiday, B. [prokoman1] (2011, 22 de diciembre). Billie Holiday-Strange fruit- HD [archivo de video]. Youtube. https://www.youtube.com/watch?v=Web007rzSOI

Pérez, R. (2015). Em el tercer mundo mestizo, de la mano de Alicia. Revista colombiana de pensamiento estético e historia del arte, (2), 123-178. https://cienciashumanasyeconomicas.medellin.unal.edu. co/images/revista-estetica-pdf/segunda_ed/4.tercermundo.pdf

Platón. (1871). La apología de Sócrates. En P. Azcárate (ed.), Platón. Obras completas (pp. 43-86).

Serres, M. (2003). Hominiscencia (J. Márquez, trad.). Le Pommier.

Serres, M. (2005). El Incandescente (L. Paláu, trad.). Le Pommier.

Serres, M. (1977). Hermes IV. (L. Paláu, trad.). Minuit.

Serres, M. (1991). El Contrato natural. Pre-Textos.

Serres, M., Pulido, M. y Castrillón, A. (1994). Drogas. Sociología: Revista de la Facultad De Sociología De Unaula, (17), 68-70. https://publicaciones.unaula.edu.co/index.php/sociologiaUNAULA/article/ view/831

Vegecio, F. (2006). Compendio de técnica militar. Cátedra.

Whitman, W. (1997). Canto a mí mismo. Losada. 